\title{
A Colônia do Sacramento, o "Jardim da América"
}

PAULO CÉSAR POSSAMAI*

Resumo: A semelhança entre o clima da Colônia do Sacramento e o de Portugal levou vários cronistas a retratar os arredores da fortaleza como um jardim europeu. Entretanto, o desenvolvimento agrícola em Sacramento não foi espontâneo, mas fruto da ação do governador, que proibiu a caça ao gado selvagem, principal recurso econômico da região, aos colonos que não cultivassem seus lotes.

Abstract: The resemblance between the climate of the Colônia do Sacramento and that of Portugal led many chroniclers to portray the surroundings of the fortress as a European garden. However, the development of farming in Sacramento was not spontaneous, but the result of the pressure from the governor, who forbade the hunting of wild cattle, the major economic source of the region, to any settler who refuse to cultivate their land.

Palavras-chave: Colonização. Agricultura. Caça.

Key words: Colonization. Farming. Hunting.

A semelhança do clima da Banda Oriental com o do Reino empolgou muitos portugueses, que julgaram poder construir um novo Portugal às margens do Rio da Prata. O governador Sebastião da Veiga Cabral (1699-1705) louvava a fertilidade das terras da Colônia do Sacramento, dizendo que elas podiam "abundar em searas, vinhas, pomares e flores da Europa, além de produzir todos os mais frutos do Brasil". Contudo, não deixava de ressaltar que, se "as terras desde Laguna até o sítio onde esteve Colônia são boas, as que estão de Colônia até o rio Uruguai são melhores e, sobretudo excelentes as que correm pelas margens do rio Uruguai". ${ }^{1}$ Comentário que não deixa dúvidas a respeito das ambições expansionistas dos portugueses.

* Doutor em História Social pela Universidade de São Paulo; professor adjunto na Universidade Federal do Rio Grande do Norte.

E.mail: paulocpossamai@hotmail.com

1 CABRAL, Sebastião de Veiga. Descrição Geográfica e Coleção Histórica do Continente da Nova Colônia da Cidade do Sacramento [1713]. Apartado de la Revista del Instituto Histórico y Geográfico del Uruguay. Montevidéu, 1965, tomo XXIV, p. 113.

Estudos Ibero-Americanos. PUCRS, v. XXX, n. 1, p. 33-46, junho 2004 
Veiga Cabral dizia ainda que, antes de 1694, a cada alqueire de trigo semeado, colhiam-se cinqüenta e, por vezes, quantidade maior, sendo que o centeio, a cevada e o milho produziam ainda mais. ${ }^{2}$ Por algum tempo, foi tão grande a produção de trigo que quando se sentiu a falta dele em Buenos Aires, o governador de Colônia ofereceu-se para vender aos portenhos mais de doze mil fanegas do cereal. ${ }^{3}$ Contudo, parece que a fertilidade do solo estava ligada à utilização de terras virgens, pois, segundo um estudo elaborado por Luís Ferrand de Almeida, seguiu-se uma certa quebra na produção do trigo com relação às excepcionais colheitas dos primeiros anos, fato que o autor relacionou à falta do sistema de rotatividade de culturas. ${ }^{4}$

Porém, mais do que pelos seus trigais, a Colônia do Sacramento ficou famosa pelas frutas e hortaliças cultivadas pelos casais em suas famosas quintas. Entre as frutas que se colhiam nos arredores do povoado, Veiga Cabral citava melões, melancias, figos, uvas e azeitonas, distinguindo os pêssegos, os quais a "sua extraordinária quantidade os faz comuns". 5 Ainda segundo o governador, o número de hortaliças como salsa, hortelã, coentro e mostarda era tão grande que muitos colhiam suas sementes para vendê-las nas demais povoações da América portuguesa.

Era lugar comum louvar a fertilidade das terras de Colônia e compará-las com vantagem às da Europa. Rocha Pitta escrevia, em princípios do século XVIII, que, em Sacramento, "o clima e o terreno são de forma próprios para a produção de flores, frutos e sementeiras da Europa, como experimentam os nossos povoadores nos muitos e deliciosos jardins, pomares, e searas que têm já cultivado naquele frutífero e vasto país". 6 Por sua vez, o alferes Silvestre Ferreira da Silva, descrevia "copiosas colheitas de trigos, e mais frutos necessários para a vida humana, que tudo estas terras produzem com vantagem às da Europa". Afirmava que nos pomares das quintas "se achavam enxertos de toda a casta de frutas das de Portugal; e assim mesmo dilatados canteiros da mais doce e mimosa hortaliça, cujo gosto, com manifesta verdade, faz competência à mais viçosa da Europa".7

2 Ibid., p. 46.

3 Relación del sitio, toma y desalojo de la Colonia... (Lima, 1705). In: Revista del Instituto Histórico y Geográfico del Uruguay. Montevidéu, 1928, tomo VI, p. 200.

4 ALMEIDA Luís Ferrand de. A Colônia do Sacramento na Época da Sucessão de Espanha. Coimbra: Faculdade de Letras da Universidade de Coimbra, 1973, p. 313.

5 CABRAL, op. cit., p. 47.

6 PITTA, Sebastião da. História da América Portuguesa [1730]. São Paulo: W. M. Jackson Inc., 1958, p. 104.

7 SYLVA, Silvestre Ferreira da. Relação do Sítio da Nova Colônia do Sacramento [1748]. Porto Alegre: Arcano 17, 1993, p. 25-26. 
De fato, apesar das restrições com que as autoridades de Buenos Aires procuravam impedir a comercialização dos grãos para fora da sua área de administração, não deve ter sido muito difícil para os portugueses, habituados ao comércio clandestino no Rio da Prata, conseguirem as sementes de que necessitavam. Longe das vistas das autoridades espanholas, os portugueses não teriam problemas em negociar com os agricultores bonaerenenses que, em sua maioria, eram pobres arrendatários que muitas vezes tinham de vender sua produção, ainda no campo, aos atravessadores, devido à falta de local apropriado para o armazenamento dos grãos. ${ }^{15}$

Mas, se não era difícil conseguir sementes, as restrições com que as autoridades espanholas procuraram impedir o acesso à campanha aos portugueses através da guarda de São João, posto militar espanhol situado a cinco léguas ao norte de Colônia, se constituíam num problema cotidiano. Respondendo aos protestos de Manuel Gomes Barbosa contra a ação das patrulhas espanholas, o governador de Buenos Aires ordenou que se lhe entregassem algumas vacas leiteiras como presente. ${ }^{16}$ Gomes Barbosa não se limitou a aceitar o presente de D. Bruno Mauricio de Zabala, pois, escrevendo sobre o bloqueio espanhol ao vice-rei, dizia-lhe que "sem embargo disso me valho da minha indústria para o gado da campanha para dar de comer a essa gente que está aqui que passa de mil e quarenta pessoas". ${ }^{17}$

De fato, as autoridades de Buenos Aires dificilmente conseguiam impedir as relações comerciais dos portugueses, que se abasteciam de gado através dos índios e mesmo dos espanhóis. Enquanto alguns casais receberam uma junta de bois, outros tiveram de comprá-las (talvez com o dinheiro que era periodicamente enviado pelo governador do Rio de Janeiro), pois uma relação de 1719 oferece uma lista de bois dados a alguns casais e outra se refere às juntas de bois mansos comprados por outros. Infelizmente, o documento não informa o porquê da diferença de tratamento. Ao todo eram 67 juntas, perfazendo um total de 134 bois mansos. ${ }^{18}$

15 GARAvagliA, Juan Carlos. El pan de cada día: el mercado del trigo en Buenos Aires, 1700-1820. Boletín del Instituto de Historia Argentina y Americana "Dr. E. Ravignami", $3^{\frac{2}{2}}$ serie, $\mathrm{n}^{\mathrm{9}} 4$, p. $19-20$.

16 Carta de D. Bruno de Zabala ao marquês de Gimaldo. Buenos Aires, 05/04/1718. In: PASTELLS e MATEOS, op. cit., tomo VI, p. 167.

17 Carta de Gomes Barbosa ao vice-rei. Colônia, 12/04/1718. Documentos Históricos. Rio de Janeiro: Biblioteca Nacional. vol. LXXI, p. 31.

18 SANTOS, op. cit., p. 5-7. 
Tudo indica que demorou bastante tempo para que os colonos conseguissem restaurar a prosperidade agrícola alcançada durante o governo de Veiga Cabral. Dificuldades em receber sementes e ferramentas embaraçavam a tarefa do governador Manuel Gomes Barbosa de favorecer o desenvolvimento agrícola em Colônia. A situação precária dos primeiros tempos arrefeceu o ânimo dos colonos, que se ressentiam da falta de apoio permanente por parte da metrópole. Por isso, o Conselho Ultramarino pedia a continuidade das expedições de socorro a Colônia, como um meio de "sossego dos novos povoadores que se mostram ali desanimados, e com algumas desconfianças da sua pouca duração e subsistência, vendo que deste Reino não são diretamente visitados e socorridos". 19

A chegada do novo governador, Antônio Pedro de Vasconcelos, em março de 1722, aliviou um pouco a tensão existente entre os colonos, que temiam a cessão de Colônia à Espanha em troca de algum equivalente, possibilidade que constava nos termos do Tratado de Utrecht, assinado em 1715. Porém, os temores só desapareceram por completo com a chegada de um navio que trouxe de Lisboa mais gente, armamentos e sementes. ${ }^{20}$

O padre espanhol Domingos Neyra, que visitou Sacramento no ano em que se deu a troca do governo local, seguindo depois para a Europa no mesmo navio em que viajou Gomes Barbosa, relatou que "as quintas que possuíam seus habitantes estão reduzidas a nada, havendo sido cada uma delas um paraíso, porque a terra é propícia a todo gênero de plantas". 21 Porém, se havia descaso com as lavouras, o mesmo não se dava com relação à pecuária. Então, oitenta e dois casais habitavam o território de Sacramento, onde havia 110 carretas e o rebanho estava calculado em 1.931 cavalos, 3.657 cabeças de gado de criação e 355 juntas de bois. ${ }^{22}$

Vasconcelos logo verificou que o pouco desenvolvimento da agricultura não se devia à má qualidade do solo, antes pelo contrário, já que um alqueire de semente geralmente produzia quarenta e cinco alqueires de grão, podendo chegar até setenta.

19 Consulta do Conselho Ultramarino. Lisboa, 14/03/1722. IHGB, Arq. 1.1.21, ff. 73-75.

20 Carta de Vasconcelos ao rei. Colônia, 25/09/1722. AHU, Colônia do Sacramento, cx. 1, doc. 76 .

21 Domingos Neyra, apud RIVEROS TULA Aníbal M. Historia de la Colônia del Sacramento. Apartado de la Revista del Instituto Histórico y Geográfico del Uruguay. Montevidéu, 1959, tomo XXII, p. 161-162.

22 "Mapa geral..." 24/10/1722, Mapoteca do Arquivo Histórico do Exército (Rio de Janeiro): S-RS-07.05.1627. 
Para o governador, as más colheitas de trigo deviam-se ao abandono da agricultura em favor da exploração do gado selvagem. ${ }^{23}$ Por isso, não deixou de lembrar à população, num discurso que se seguiu a sua posse no governo, que a Coroa tinha feito grandes investimentos a fim de que os povoadores promovessem a conservação e o crescimento da Colônia do Sacramento. Alertou então que "se o tempo que se tinha gasto com os laços se empregara nos arados, e o benefício que se aplica aos couros se repetira nas lavouras, seriam tão avultadas as colheitas quanto promete a fertilidade da terra". ${ }^{24}$

Quem pensou que a preocupação do governador com a agricultura não passou de mero exercício de eloqüência, logo verificou que Vasconcelos falava sério, pois o mesmo impediu a saída para a campanha de todos os que não tratassem de semear e cultivar seus lotes. A atitude enérgica de Vasconcelos contribuiu para que, no ano da sua posse, os campos fossem semeados com mais de mil e cem alqueires de sementes de trigo. Além da preocupação do governador em fixar a população à terra, o incentivo à agricultura tinha também o objetivo de tornar a Colônia do Sacramento autosuficiente na produção de alimentos, libertando a guarnição da dependência das remessas de farinha de mandioca que vinham do Rio de Janeiro.

Contudo, apesar das medidas coercitivas adotadas pelo governador para promover a triticultura, a praga da "ferrugem", que há dois anos atacava os trigais, continuou a fazer estragos. A soma da má colheita aos nove meses em que não chegou nenhuma remessa de farinha de mandioca do Rio de Janeiro, obrigou muitos moradores a comprar pão aos espanhóis da guarda de São João, em 1722, os quais não perderam a oportunidade de elevar os preços frente à forte procura da sua produção pelos portugueses..$^{25}$

23 Tudo leva a crer que então os portugueses já estavam bem adaptados aos costumes vigentes no Rio da Prata, assimilando o desprezo que os súditos espanhóis que habitavam a região platina votavam à agricultura. Segundo Rodríguez Molas, para conseguir mão-de-obra agrícola na campanha de Buenos Aires, as autoridades obrigavam mulatos, índios e mestiços a trabalhar a terra, já que para os espanhóis a agricultura era considerada um ofício para escravos, enquanto que para os criollos, que se dedicavam à pecuária, não era uma atividade bem vista por ser realizada a pé. Segundo Félix de Azara, "os pastores consideram os agricultores mentecaptos, pois se se tornassem pastores, viveriam sem trabalhar e sem necessidade de comer pasto, como os cavalos, porque assim chamam as saladas, legumes e hortaliças". Apud RODRÍGUEZ MOLAS, Ricardo. Historia Social del Gaucho. Buenos Aires: Marú, 1968, p. 169.

24 Carta de Vasconcelos ao rei. Colônia, 25/09/1722. AHU, Colônia do Sacramento, cx. 1 , doc. 76 .

25 Carta de Vasconcelos ao rei. Colônia, 25/09/1722. AHU, Colônia do Sacramento, cx. 1, doc. 76 . 
A situação continuou crítica em princípios do ano seguinte, quando uma tempestade, ocorrida pouco antes da colheita, devastou os trigais, enquanto o pequeno número dos legumes colhidos só serviu para garantir a provisão de sementes. ${ }^{26}$

Porém, no decorrer do ano de 1723 , a situação melhorou bastante. Simão Pereira de Sá informa que o número de moradores nos arredores de Sacramento era superior ao número dos 350 vizinhos que, então, viviam na povoação. As quintas, que se estendiam até duas léguas da praça, estavam semeadas de trigais, pomares, hortas e jardins, onde abundavam vinhas e aves. Já nas estâncias, que se localizavam a dezesseis léguas, passava de cem mil o número de vacas, sendo que "o número dos bois, éguas e cavalos para a produção não era inferior". 27

Entretanto, a prosperidade agrícola era ameaçada pela falta de segurança dos colonos, que estavam sempre propensos a ver suas lavouras arrasadas por investidas dos índios ou dos espanhóis, constituindo-se num forte foco de tensão cotidiana que poderia evoluir até levar à deserção. Sobre tal perigo, alertava o jesuíta Diogo Soares, que defendia a construção de poderosas fortificações, pois, em caso contrário afirmava que "os moradores, vendo-se expostos a padecer em suas próprias casas o que sofrem todos os dias na campanha aos castelhanos, buscarão em outra parte da América [lugar onde] vivam mais seguros, e sem o temor e risco, que são comumente certos em uma praça fronteira, exposta e sem defesa". ${ }^{28}$

De fato, a insegurança na campanha era uma preocupação constante dos povoadores. Em 1722, um militar português conseguiu entreter uma patrulha indígena comandada pelos jesuítas "pela sua afabilidade e por meio de um regalo que à custa da sua fazenda ofereceu aos ditos missionários".29 A negociação deu tempo para que os agricultores conseguissem fazer a colheita do trigo maduro. Dois anos depois, respondendo à tentativa portuguesa de povoar o sítio de Montevidéu, os espanhóis atearam fogo às searas de trigo, originando um grande incêndio que demorou doze dias para ser extinto pelos agricultores e soldados.

26 Carta de Vasconcelos ao rei. Colônia, 12/02/1723. AHU, Colônia do Sacramento, cx. 1 , doc. 100 .

27 SÁ, Simão Pereira. História Topográfica e Bélica da Nova Colônia do Sacramento do Rio da Prata. [1737] Porto Alegre: Arcano 17, 1993, p. 58.

28 Carta do padre Diogo Soares ao rei. Colônia, 27/06/1731. In: MONTEIRO, Jonathas C. Rego. A Colônia do Sacramento (1680-1777). Porto Alegre: Globo, 1937, vol. 2, p. 80-81.

29 Consulta do Conselho Ultramarino. Lisboa, 26/02/1729. In: Anais da Biblioteca Nacional. Rio de Janeiro, 1934, vol. XLVI, p. 3-4. 
Depois da fortificação de Montevidéu pelos espanhóis, o governador de Buenos Aires criou uma companhia de "migueletes", cavaleiros cuja função era impedir o acesso dos portugueses à campanha e que tinham permissão para ficar com todas as presas que fizessem ao inimigo. Em busca de butins, eles passaram a atacar as quintas das proximidades de Colônia, onde roubavam o gado e assaltavam as pessoas que encontravam pelo caminho.30 Contra a ação dos migueletes, que "talavam os campos, roubavam os lavradores e infestavam escandalosamente as vizinhanças da praça", o governador Vasconcelos escreveu a D. Bruno Zabala. Antônio Pedro de Vasconcelos queixou-se ao rei que a resposta irônica do governador de Buenos Aires ao seu protesto foi que "se para emenda necessitassem de disciplina, buscássemos os meios proporcionados do castigo". ${ }^{31}$

Ciente de que tal resposta era uma convocação para uma demonstração de força, Vasconcelos ordenou que vinte cavaleiros, sob as ordens do alferes Pedro Pereira Chaves, atacassem os migueletes. O pequeno grupamento português localizou o acampamento espanhol às margens de um riacho. Um ataque surpresa conseguiu destroçar o inimigo, pondo em fuga alguns e matando seis deles, entre os quais seu comandante, o capitão Juan de Burgos. Segundo Simão Pereira de Sá, "ficou deste modo desembaraçada a campanha, quieto o subúrbio, e seguros os lavradores que, livres de tão arriscados precipícios, semeavam já o grão com boas esperanças de fruto". ${ }^{32} \mathrm{O}$ alferes e seus soldados ainda puderam repartir entre si os cento e cinqüenta cavalos apresados aos migueletes. ${ }^{33}$

Passados os anos críticos da luta por Montevidéu, os colonos puderam desfrutar de um curto período de paz. Contudo, as secas e as pragas continuaram sendo um flagelo para os agricultores. A colheita de 1726 foi fraca devido a uma grande seca que já durava dois anos, mas, mesmo assim, conseguiu-se colher quase dez mil alqueires de trigo, porém a produção das frutas e legumes não correspondeu à semeadura. ${ }^{34}$ Nos anos seguintes a produção deve ter aumentado, pois, se então a dízima do trigo havia rendido $172 \$ 155$ à Fazenda Real. Em 1727 rendeu $360 \$ 375$ e, no seguinte, 402\$000.35

30 Consulta do Conselho Ultramarino. Lisboa, 28/04/1725. IHGB, Arq. 1.1.21, f. 315.

31 SÁ, op. cit., p. 61.

32 Ibid.

33 Consulta do Conselho Ultramarino. Lisboa, 28/04/1725. IHGB, Arq. 1.1.25, ff. 315$315 \mathrm{v}$.

34 Carta de Vasconcelos ao rei. Colônia 13/05/1726. AHU, Colônia do Sacramento, cx. 2, doc. 165 .

35 Carta de Vasconcelos ao rei. Colônia, 29/07/1729. AHU, Colônia do Sacramento, cx. 2 , doc. 215 . 
Em 1730, apesar da praga da "ferrugem", colheram-se mais de vinte mil alqueires de trigo. ${ }^{36}$ Já no ano seguinte, a conjugação da seca e do frio excessivo causou grandes perdas nas searas, porém, como se tinha semeado uma grande quantidade de terreno a fim de produzir um excedente para vender no Brasil, colheram-se mais de treze mil alqueires. ${ }^{37}$ Em 1732, o governador escrevia ao rei que "a colheita de trigo (suposto [que] lhe dera ferrugem) chegara a vinte mil alqueires". 38

Em 1734, uma seca muito forte fez com que só se salvassem as sementes, prejudicando também as demais lavouras e acabando com o pasto dos animais. Para poder alimentar a guarnição, o contratador do pão de munição teve de recorrer a outros centros produtores, mandando comprar trigo em Buenos Aires e buscar três mil alqueires de farinha de mandioca em Paranaguá. ${ }^{9}$ Em fevereiro de 1735, Vasconcelos escrevia que a colheita do trigo havia sido excelente, pois já se acabara a terrível seca dos anos passados. Acrescentava ainda que, como a seara não havia ainda acabado, não sabia quanto renderia o dízimo, o qual venderia a 550 mil réis ao novo contratador do pão de munição arrematado no Rio de Janeiro. 40

Embora o trigo se constituísse no principal plantio na Colônia do Sacramento, os documentos também fazem referência a outras plantações, como cevada e milho ${ }^{41}$ que, tudo indica, se destinavam sobretudo ao sustento dos escravos.42 Deve-se lembrar que a insistência do governador Vasconcelos em promover a triticultura ligava-se ao fato de que os dízimos da sua produção serviam de alimentação à tropa. Outro fator importante a se ressaltar

36 Carta de Vasconcelos ao rei. Colônia, 05/04/1730. AHU, Colônia do Sacramento, cx. 2 , doc. 220.

37 Carta de Vasconcelos ao rei. Colônia, 05/04/1731. AHU, Colônia do Sacramento, cx. 5 , doc. 226 .

38 Consulta do Conselho Ultramarino. Lisboa, 02/09/1733. IHGB, Arq. 1.1.26, ff. 193-195.

39 Carta de Vasconcelos ao rei. Colônia, 17/02/1734. AHU, Colônia do Sacramento, cx. 3, doc., 276.

40 Consulta do Conselho Ultramarino. Lisboa, 27/10/1735. IHGB, Arq. 1.1.26, ff. 240-242.

41 A mesma situação dava-se então na campanha de Buenos Aires, onde dominavam as lavouras de trigo, enquanto a produção de cevada e de milho tinha uma importância bastante secundária. Cf. Juan Carlos GARAVAGLIA, "Producción cerealera y producción ganadera en la campaña porteña: 1700-1820", in: Estructuras Sociales y Mentalidades en América Latina. Buenos Aires: Biblos, 1990, p. 222.

42 Em 1730, Vasconcelos informava o rei sobre grandes perdas nas searas devidas à seca e ao frio excessivo, contudo ressaltava que "a perda do milho foi menor e se espera haja grande porção para o sustento dos escravos". Cf. Carta de Vasconcelos ao rei. Colônia, 05/04/1730. AHU, Colônia do Sacramento, cx. 2, doc. 226. 
é que o cultivo do trigo exigia o trabalho na lavoura somente durante os períodos da semeadura e da colheita, ${ }^{43}$ possibilitando aos trabalhadores alguns meses livres, nos quais podiam se dedicar a outras tarefas, como a pecuária e a extração de couros, que se constituía no principal recurso econômico da região platina.

Outra cultura que atraiu a atenção das autoridades foi a do linho-cânhamo, matéria-prima essencial para a confecção do cordame utilizado pela marinha. Antônio Rodrigues Carneiro, principal responsável pela vinda dos transmontanos para o Prata, pretendia iniciar a cultura do linho-cânhamo em Colônia e por isso incluiu o pedido da superintendência dessa cultura entre os favores que solicitara à Coroa pela sua contribuição em auxiliar o repovoamento de Sacramento.44 Em 1725, o governador Vasconcelos informou à Coroa que os dois alqueires de sementes de linhocânhamo enviados para Colônia por Pedro da Costa Lima tinham produzido bem, embora não tivessem crescido tanto quanto nas plantações de Trás-os-Montes. ${ }^{45}$

No relato que Silvestre Ferreira da Silva fez dos estragos causados pelos espanhóis no cerco que se prolongou de 1735 a 1737, podemos ter uma idéia da produção agropecuária da Colônia do Sacramento: 2.455 alqueires de trigo, legumes, pomares, vinhas (algumas com mais de noventa mil pés de bacelo) além de grande quantidade de aves e animais domésticos criados pelos casais. Nas estâncias, a perda estava orçada em 18.443 "cavalgaduras de toda a espécie", 2.332 ovelhas, 87.204 cabeças de gado vacum crioulo, além de 104 carretas, instrumentos e madeiras e 46 escravos lavradores. 46

Outra relação dos prejuízos causados pelas tropas espanholas informa-nos que existiam duzentos e quarenta quintas nos arredores de Sacramento, sendo que nem todas tinham a mesma extensão ou valor. As propriedades do tenente-general engenheiro Pedro Gomes de Figueiredo estavam orçadas em nove contos, setecentos e quatro mil e quinhentos réis; as do capitão de cavalaria

43 Em fins de maio, junho e parte de julho se deveria proceder à aragem e à semeadura, sendo que a volta aos campos só era necessária em dezembro e, sobretudo, em janeiro e parte de fevereiro para a colheita. Cf. GELMAN, Jorge. ¿Gauchos o campesinos? In: Anuário IEHS. Tandil: Universidad Nacional del Centro de la Provincia de Buenos Aires, 1987, $\mathrm{n}^{2} 2$, p. 58 .

44 Relatório do conselheiro Antônio Rodrigues da Costa sobre o transporte dos casais transmontanos. In: Anais da Biblioteca Nacional. Rio de Janeiro, 1934, vol. XLVI, p. 113-114.

45 Carta de Vasconcelos ao rei. Colônia, 04/061725. AHU, Colônia do Sacramento, cx. 2 , doc. 140 .

46 SYLVA, op. cit., p. 106-107. 
Inácio Pereira da Silva em quinze contos e quinhentos e quarenta e cinco mil réis; enquanto a quinta do capitão de cavalaria da ordenança João da Costa Quintão valia vinte e seis contos, duzentos e sessenta e quatro mil e duzentos e cinqüenta réis. ${ }^{47}$

Como podemos constatar, a partir da leitura deste relato, as propriedades mais valiosas não pertenciam aos casais povoadores, mas sim a destacados elementos da sociedade local. Numa certidão passada a Caetano do Couto Veloso, escrivão da Fazenda Real, o governador Vasconcelos informava que o mesmo era "um dos mais avantajados lavradores", dono de várias quintas situadas nos arredores da praça, onde abundavam pomares, vinhas, lavouras, gado vacum e cavalar. Poucos meses antes do início do sítio espanhol, Couto Veloso inaugurara uma olaria, na qual investira mais de dois mil cruzados na compra de madeiras e escravos. Somados, os bens de extramuros do escrivão foram avaliados pelo mesmo em três contos e oitocentos e quarenta mil réis em 1736.48

Além dos desastres naturais, como secas e invernos rigorosos, e das incursões indígenas e espanholas que por vezes destruíam as plantações, problemas causados pelo processo de distribuição das terras também dificultaram o desenvolvimento da agricultura na Colônia do Sacramento. Quando se discutiram, em Lisboa, os incentivos a serem dados aos casais povoadores, o parecer do conselheiro Antônio Rodrigues da Costa foi que se deveria dar a cada casal dez jeiras de terra de sesmaria nas proximidades da praça e uma légua de terra em quadra também em sesmaria na campanha. Por sua vez, Antônio Rodrigues Carneiro, líder dos casais, deveria receber esses números em dobro. 49

A carta régia de 9 de setembro de 1719 regulamentou a maneira pela qual o governador deveria proceder à distribuição das sesmarias aos casais. Porém como persistia a controvérsia com as autoridades de Buenos Aires sobre a questão do território de Colônia, Gomes Barbosa julgou melhor não conceder títulos de propriedade, limitando-se a distribuir os lotes entre soldados e colonos. ${ }^{50}$ A situação não era nova, pois os colonos que lá viviam antes

47 Extrato das perdas e danos executadas pelas tropas espanholas... In: Revista do Instituto Histórico e Geográfico do Rio Grande do Sul. Porto Alegre, 1945, ñ 99 , p. $52-53$.

48 Certificados referentes a los servicios y méritos funcionales de Caetano de Couto Vellozo... Archivo Regional de Colonia. Reg. 217, 38 T5, doc. 3, ff. 31-32.

49 Relatório do conselheiro Antônio Rodrigues da Costa sobre o transporte dos casais transmontanos. In: Anais da Biblioteca Nacional. Rio de Janeiro, 1934, vol. XLVI, p. 113-114.

50 Carta de Gomes Barbosa ao rei. Colônia, 26/12/1719. AHU, Colônia do Sacramento, cx. 1 , doc. 55 . 
da evacuação ordenada em 1705 também não tinham a posse da terra que cultivaram, reconhecida através de documentos. Luís Ferrand de Almeida relata que a documentação da época fala simplesmente em dar terras, mas não há qualquer referência ao sistema de sesmarias ou à celebração de contratos agrários..$^{51}$

Embora não saibamos exatamente como se deu a distribuição dos terrenos, o fato é que ela não tardou a ser contestada pelos povoadores, os quais acusaram o governador de se beneficiar do processo. Para se defender das acusações, Gomes Barbosa pediu o testemunho de pessoas importantes na comunidade local, como o sargento-mor Antônio Rodrigues Carneiro, que atestou a inocência do governador, acusado de pedir dinheiro pela doação das terras. ${ }^{52}$ Também o padre Antônio do Vale, superior da residência dos jesuítas em Colônia, atestou que Gomes Barbosa "repartiu os chãos, assim dentro como fora da fortaleza, aos casais e mais moradores, que lhe pediram, sem intervir nisto interesse algum da sua parte". 53

Porém, numa representação à Coroa, os moradores queixaramse de que, apesar da promessa de que cada casal receberia três jeiras de terra nas proximidades da praça, não tinham recebido nada além de um terreno onde edificaram suas casas, sendo-lhes necessário "semear muito longe seus trigos". ${ }^{44}$ Com relação à acusação de que os oficiais militares tinham sido privilegiados com a posse das terras que se situavam mais perto da povoação, o governador Vasconcelos informou o rei de que os moradores podiam fazer suas lavouras no lugar onde escolhessem e que todos fugiam dos arredores de Colônia por serem terras demasiado secas. .55

$\mathrm{Na}$ verdade, o problema principal não consistia na maior ou menor fertilidade do solo, mas sim na segurança, pois quanto mais longe da fortificação, maior era o perigo de sofrer algum ataque, fosse por parte da guarda espanhola, fosse por parte dos índios. Procurando resolver o problema das investidas dos espanhóis e assegurar a propriedade através de títulos, os colonos pediram ao rei para que se buscasse o fim da controvérsia sobre o território de Sacramento com a corte de Madri. O pedido dos moradores não

51 ALMEIDA, op. cit., p. 88.

52 Certificado de Antônio Rodrigues Carneiro, 12/01/1720. AHU, Colônia do Sacramento, cx. 1, doc. 58 .

53 Certificado do padre Antônio do Vale, 05/12/1719. AHU, Colônia do Sacramento, cx. 1, doc. 58 .

54 Representação dos povoadores da Colônia do Sacramento. AHU, Rio de Janeiro, cx. 33, doc. 7695 .

55 Carta de Vasconcelos ao rei. Colônia, 09/05/1732. AHU, Rio de Janeiro, cx. 33, doc. 7694 . 
deixou de escandalizar Vasconcelos, que alegou que essa era uma "matéria muito alheia das suas obrigações e desnecessária em tempo que põe estâncias e levam as suas lavouras onde os convida o apetite". 56

Vasconcelos não deixou de se contradizer com essa afirmação, pois anteriormente havia escrito ao rei que a resolução da questão sobre o território de Sacramento era essencial para garantir o aumento na produção de alimentos, a fim de livrar a guarnição da dependência das remessas de farinha do Rio de Janeiro. Argumentava, então, que o domínio legal sobre o território garantiria a segurança dos lavradores, os quais poderiam expandir as suas lavouras para o interior da campanha, o que, por sua vez, asseguraria o aumento dos dízimos da produção, com os quais poder-se-ia prover o sustento da guarnição. ${ }^{57}$

Porém, as queixas contra os oficiais militares não se restringiam à disputa das terras mais próximas à fortaleza. Os colonos também reclamavam da perda de parte das colheitas devido à invasão das suas lavouras pelo gado e cavalos dos poderosos e, principalmente, pela concorrência que os grandes proprietários de terras, geralmente militares e comerciantes, lhes moviam na produção do trigo. Como nas terras dos oficiais não havia problema de falta de mão-de-obra, uma vez que eram cultivadas por escravos "e outras pessoas que por respeito lhe lavram e semeiam o dito campo", os militares conseguiam uma produção maior que a média. Os colonos pediam então ao rei que proibisse o plantio aos oficiais militares, alegando que, como o trigo "não tem saída para fora da terra [de Colônia], não tem o povo conveniência em plantar mais que para o seu sustento e de suas famílias [e] que se vendem algum para se remediarem é barato, o que não sucede aos ditos oficiais, porque como não têm necessidade de guardar para mais tarde e o reputam como querem". 58

Em suma, insegurança, catástrofes naturais e contestações ao modo como foi feita a distribuição das terras, contribuíram para gerar um cotidiano bastante difícil para as pessoas que se dedicavam à agricultura no território da Colônia do Sacramento, realidade que seria muito diferente do que os idílicos relatos sobre a fertilidade do solo platino nos levam a pensar.

56 Carta de Vasconcelos ao rei. Colônia, 09/05/1732. AHU, Rio de Janeiro, cx. 33, doc. 7694.

57 Carta de Vasconcelos ao rei. Colônia, 14/07/1728. AHU, Colônia do Sacramento, cx. 2, doc. 199.

58 Representação dos povoadores da Colônia do Sacramento. AHU, Rio de Janeiro, cx. 33 , doc. 7695 . 